\title{
Perancangan Game Edukasi Agama Katolik dengan Metode Finite State Machine
}

\author{
${ }^{1}$ Brigytta Quinny Novitri, ${ }^{2}$ Handy Kusuma, ${ }^{3}$ Ponti Harianto \\ STMIK Pontianak, Jl. Merdeka No. 372 Pontianak, 0561-735555 \\ Jurusan Teknik Informatika, STMIK Pontianak, Pontianak \\ e-mail: ${ }^{1}$ brigyttaquinny@gmail.com, ${ }^{2}$ handykusuma22041992@gmail.com. \\ pontihariantoss@gmail.com
}

\begin{abstract}
Abstrak
Pengetahuan beragama Katolik sangatlah penting karena menjadi sebuah sarana dalam menjadi manusia yang beriman, toleransi, memahami ajaran cinta kasih, bermoral, dan bertaqwa kepada Tuhan Yang Maha Esa. Selain memperdalam materi agama Katolik lewat retret, sekolah minggu, dan lain-lain, pembelajaran juga dapat dilakukan dengan game. Game edukasi dirancang sebagai sarana pendidikan dengan menyisipkan materi pembelajaran untuk mengajarkan user suatu pembelajaran, pemahaman dan untuk melatih kemampuan pengguna yang memainkannya. Metode perancangan menggunakan metode Finite State Machine. metode pengembangan menggunakan metode pengembangan Game Development Life Cycle. Teknik permodelan menggunakan UML (Unified Modeling Language). Game menggunakan bahasa pemrograman Construct 2. Pengujian menggunakan uji kelayakan, untuk mendapatkan masukkan secara publik maka game ini akan direview oleh 15 responden. Instrument untuk membagikan kuisioner akan dibagikan dengan google forms. Kesimpulan dari penelitian ini adalah perancangan game edukasi pendidikan agama Katolik sudah dapat menghasilkan output yang diharapkan yaitu memberikan fitur tingkat difficulty easy dan normal, animasi, game kuis pertanyaan, dan menyusun doa yang dapat dijalankan pada PC (personal computer).
\end{abstract}

Kata kunci-Game Edukasi, Finite State Machine, Agama Katolik, Game Development Life Cycle.

\section{Abstract}

Catholic knowledge is very important because it is a means of being humans that understanding about faith, tolerance, understanding the teachings of love, morality, and devotion to God Almighty. In addition to deepening the material of Catholic religion through retreats, Sunday schools, etc., learning can also be done with games. Educational games are designed as a means of education by inserting learning materials to teach users a learning, understanding and to train the ability of users who play it. The design method uses the Finite State Machine method. development methods using the Game Development Life Cycle development method. Modeling techniques using UML (Unified Modeling Language). The game uses the Construct 2 programming language. Testing uses acceptance testing, to get public input, this game will be reviewed by 15 respondents. Instrument to distribute questionnaires will be shared with google forms. The conclusion of this study is the design of Catholic religious education educational games can produce the expected output which provides easy and normal difficulty level features, animation, quiz game questions, and compile prayers that can be run on a PC (personal computer).

Keywords-Education Game, Finite State Machine, Catholic Religion, Game Development Life Cycle

\section{PENDAHULUAN}

Media pembelajaran mengikuti perkembangan teknologi yang telah ada. Salah satu perkembangan teknologi yang diminati dengan mengkemas materi pembelajaran ke dalam sebuah game edukasi. Game edukasi adalah game yang dirancang untuk pendidikan dengan menyisipkan materi pembelajaran tertentu [1]. aplikasi simulasi yang menggunakan media game telah terbukti dapat meningkatkan motivasi belajar pelajar dari $49.5 \%$ menjadi $78 \%$ [2]. Game 
edukasi khusus dirancang untuk mengajarkan user suatu pembelajaran tertentu, pengembangan konsep dan pemahaman dan membimbing mereka dalam melatih kemampuan mereka, serta memotivasi mereka untuk memainkannya [3]. User yang menjadi sasaran pemain game edukasi pendidikan agama Katolik yaitu untuk kalangan tingkat SD (Sekolah Dasar).

Topik agama Katolik dipilih karena pendidikan agama merupakan pendidikan yang sangat penting untuk diajarkan kepada anak-anak dimana orang tua memiliki tanggung jawab penuh terhadap perkembangan iman anak. Orang tua Katolik sudah seharusnya mengajarkan ilmu dasar mengenai agama Katolik kepada anak-anaknya seperti kisah nabi yang terdapat pada kitab suci, Namun di zaman modern kini anak-anak pada saat ini lebih memilih untuk bermain game dibandingkan dengan membaca kitab suci. sehingga Agama katolik dikemas ke dalam sebuah game edukasi maka akan membuat proses belajar mengajar pada pendidikan anak yang notabenenya merupakan dunia bermain menjadi lebih menyenangkan dan memudahkan anak untuk memahami tentang moral agama yang dianutnya.

Pendidikan Agama Katolik adalah usaha yang dilakukan secara terencana dan berkesinambungan dalam rangka mengembangkan kemampuan peserta didik untuk memperteguh iman dan ketakwaan kepada Tuhan Yang Maha Esa sesuai dengan agama Katolik[4]. Tujuan pendidikan agama katolik yaitu agar peserta didik memiliki kemampuan untuk membangun hidup yang semakin beriman. [4]. Pendidikan Agama membentuk akhlak mulia sekaligus peningkatan spiritual. Dengan demikian peserta didik tidak hanya cerdas otaknya akan tetapi juga cerdas hatinya [5]. Perilaku keagamaan peserta didik dipengaruhi oleh beberapa faktor selain faktor pengajaran di sekolah, yaitu faktor media, bimbingan orang tua, dan bimbingan agama yang diperoleh dari masyarakat [6]. Perancangan game edukasi pendidikan agama Katolik menggunakan metode finite state machine.

Penggunaan metode finite state machine sangat cocok sebagai basis perancangan perangkat lunak pengendalian yang real time yang memiliki keuntungan yaitu dapat mendekomposisi aplikasi yang relatif besar hanya menggunakan sejumlah kecil item state [7] . Finite state machine terdiri dari serangkaian state yang menentukan keputusan dimana setiap state dapat berpindah ke state lainnya jika telah memenuhi kondisi yang telah ditentukan sebelumnya. Penerapan Finite State Machine pada game edukasi berguna untuk menentukan alur sistem pada game yaitu seperti untuk mengatur waktu timer pada game, mengatur perilaku score, dan mengatur jalannya sistem pada game [7].

Pola dari game edukasi ini terbagi menjadi dua bagian. pola pertama yaitu pola dalam cara menyajikan cerita game dengan mengkemasnya kedalam bentuk animasi, terdapat dialogdialog untuk memperjelas cerita game, pola/karakter kedua yaitu cara menyajikan edukasi yang terdiri dari tiga cara yaitu pertanyaan kuis, dan penyusunan doa. Game ini menawarkan cerita berupa petualangan seorang pastor dalam mencari alkitab, ketika perjalanan para devil akan menghalangi pastor dalam perjalanan dan cara untuk mengalahkan devil tersebut adalah dengan cara menjawab dengan benar pertanyaan seputar agama Katolik. Akhir cerita pastor akan mendapatkan alkitab atau gagal dalam perjalanan jika pemain tidak memenuhi target score dalam game.

Sebelumnya telah dilakukan sebuah penelitian yang berkaitan dengan topik ini pada studi kasus yang berbeda yaitu melakukan penelitian dalam penerapan algoritma fisher-yates pada pengacakan soal game aritmatika. Model pengembangan sistem menggunakan metode Rapid Application Development, perancangan menggunakan algoritma fisher-yates shuffle yang bertujuan untuk menghasilkan sebuah game edukasi yang dapat melatih ketangkasan/kecepatan berhitung dan operasinya [8].

Dari penelitian diatas, yang membedakan dengan penelitian kali ini dengan penelitian sebelumnya adalah dengan mengembangkan sebuah perangkat lunak game edukasi dengan objek yang berbeda yaitu materi pembelajaran agama Katolik dengan menggunakan metode finite state machine karena pada penelitian sebelumnya belum pernah ada yang menggunakan metode tersebut. Bahasa pemrograman dengan menggunakan Construt 2 dengan aplikasi bantuan seperti Photoshop. Game edukasi agama Katolik yang dikembangkan tersebut akan dikemas menjadi sebuah game edukasi yang interaktif untuk memudahkan pengguna dalam 
menyerap materi pembelajaran yang dikemas dalam sebuah game edukasi pembelajaran agama Katolik dengan menggunakan metode finite state machine.

\section{METODE PENELITIAN}

Penelitian ini berbentuk survey. Dalam prosedur ini, peneliti melakukan survey untuk mengumpulkan data kuantitatif berupa nilai angka dengan menggunakan angket atau kuesioner untuk memperoleh hasil statistik berupa presentase uji kelayakan pada game edukasi. Penulis membuat daftar pertanyaan sebanyak 10 butir pertanyaan dengan menggunakan google form dengan responden sebanyak 15 orang. Metode penelitian menggunakan penelitian eksperimen. Instrumen penelitian menggunakan teknik pengumpulan data studi literatur, dokumentasi, observasi, dan angket/kuesioner. Pada penelitian ini, penulis menggunakan variabel tunggal yaitu pengaruh perancangan game edukasi pendidikan agama Katolik dengan metode Finite State Machine dan Fisher-yates Shuffle untuk anak SD (Sekolah Dasar). Selanjutnya untuk proses pembuatan game edukasi menggunakan model pengembangan Game Development Life Cylce versi Heather Chandler's sebagai metode perancangan game edukasi pendidikan agama Katolik yang terdiri dari empat tahapan [9].

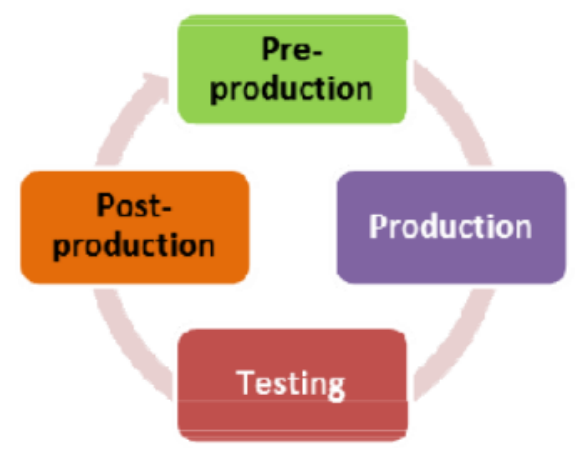

Gambar 1 Tahapan Game Development Life Cycle

Empat tahapan Game Development Life Cycle (gambar 1):

a. Tahap Pre-Production / pra produksi yaitu merupakan tahap mendefinisikan desain game dan perencanaan proyek yang akan dikerjakan. Setelah desain dan rencana telah diperbaiki dan disetujui, maka akan dilanjutkan ke tahapan produksi.

b. Tahap Production / Produksi yaitu merupakan tahap yang berhubungan dengan penciptaan dari segi aspek teknis dan artistik.

c. Tahap Testing / Uji coba yaitu merupakan tahapan untuk menguji permainan dan perbaiki kesalahan-kesalahan yang terdapat pada game. Saat membangun adalah dianggap selesai untuk satu siklus.

d. Tahap Post-Production / pasca produksi yaitu merupakan tahap yang dilakukan untuk mengantarkan arus dokumentasi dan kegiatan aktivitas selanjutnya [9].

\section{HASIL DAN PEMBAHASAN}

Pembahasan terhadap hasil penelitian dan pengujian yang diperoleh disajikan dalam bentuk uraian teoritik, baik secara kualitatif maupun kuantitatif.Hasil percobaan sebaiknya ditampilkan dalam berupa grafik atau pun tabel. Untuk grafik dapat mengikuti format untuk diagram dan gambar.

\section{Pre Production}

Pada tahap pra produksi dilakukan pembuatan konsep game seperti menentukan judul game, target dari pemain game, tujuan membuat game, genre game, menentukan jalan cerita, mendesain karakter, dan lain-lain. Judul dalam perancangan game edukasi agama Katolik dengan metode Finite State Machine, Penulis memilih judul game yaitu "Hillige Reis" target pengguna ditujukan kepada anak-anak khususnya yang masih berada pada usia SD (Sekolah 
Dasar). Tujuan dari pembuatan game ini adalah sebagai sarana hiburan, untuk menambah wawasan bagi pengguna yang memainkannya, dan melatih otak dalam berpikir cepat yang dikemas kedalam sebuah game edukasi sehingga lebih menarik dan tidak membosankan. Jenis Game / genre game yang dibuat oleh penulis adalah game bergenre edukasi, kuis, dan puzzle.Teknik Pembuatan Game / Tools menggunakan teknik hierarki dua dimensi dimana pembuatan game menggunakan aplikasi Construct 2. Pembuatan karakter game dan background menggunakan Adobe Photoshop. Serta penambahan Assets (Villain, Texture, Sound, dll) dari berbagai resources. Gambar dalam pembuatan game seperti karakter game dan animasi adalah file dengan format .JPG dan .PNG. Format audio yang digunakan penulis dalam pembuatan game adalah file berformat .ogg. Berikutnya pada tahap pra produksi juga dilakukan perancangan UML yang terdiri dari use case diagram, activity diagram, sequence diagram, dan class diagram.

Use case diagram berfungsi untuk menjalaskan manfaat dan fungsionalitas suatu sistem yang akan dirancang. Dari use case dapat dilihat pada game 'Hillige terdapat dua actor yaitu player dan system, ketika pemain membuka game, game akan menampilkan splash screen dan tampilan halaman menu utama, pada menu awal terdapat tombol bantuan dan tentang untuk melihat informasi seputar game, tombol start ditekan untuk memulai game, setelah menekan tombol start player dapat memilih difficulty pada game, setelah itu intro pada game adalah cerita singkat dari game ini, dan pada akhirnya game dapat dimainkan, hasil outcome game yaitu game over yang berarti game telah berakhir (Gambar 2).

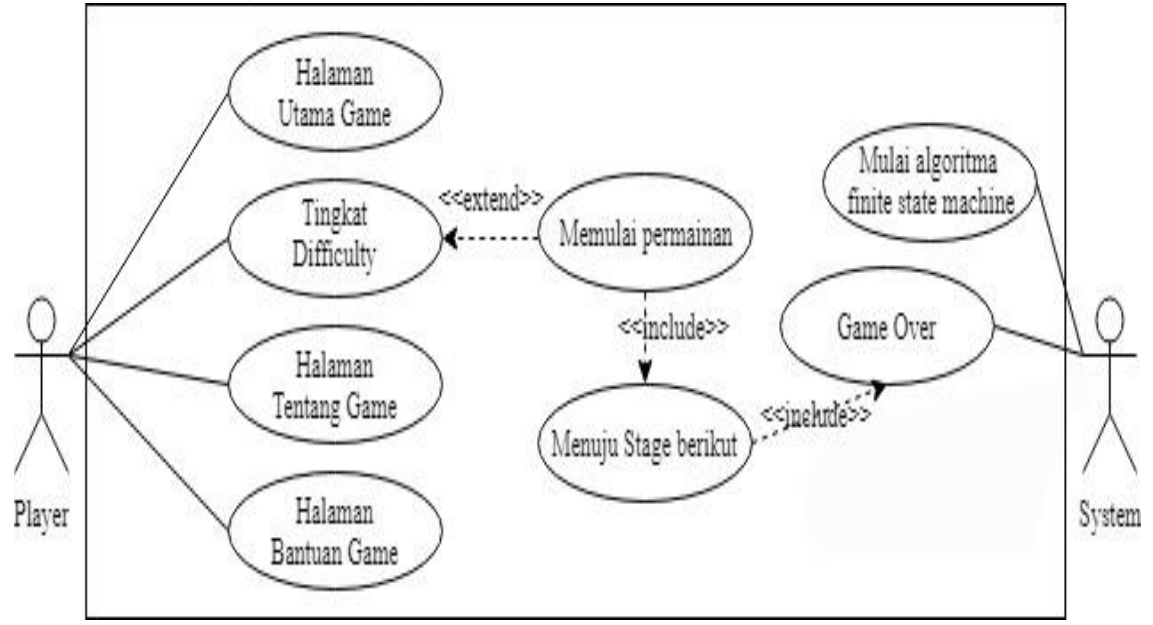

Gambar 2 Use case diagram Game Hillige Reis

Activity Diagram pada gambar menggambarkan arus permainan dari pemulaan sampai dengan berakhirnya game, pada saat permulaan game, pemain dapat menekan tiga tombol yaitu, tombol bantuan, tombol tentang, dan tombol mulai/start, dengan menekan tombol bantuan, menu bantuan akan muncul dilayar, begitu juga dengan tombol tentang, dan tombol stat akan menampilkan menu pilihan difficulty pada game, sesudah memilih menu difficulty, game akan dimulai, hasil akhir dari game ini hanya ada dua yaitu menang/kalah (Gambar 3). 


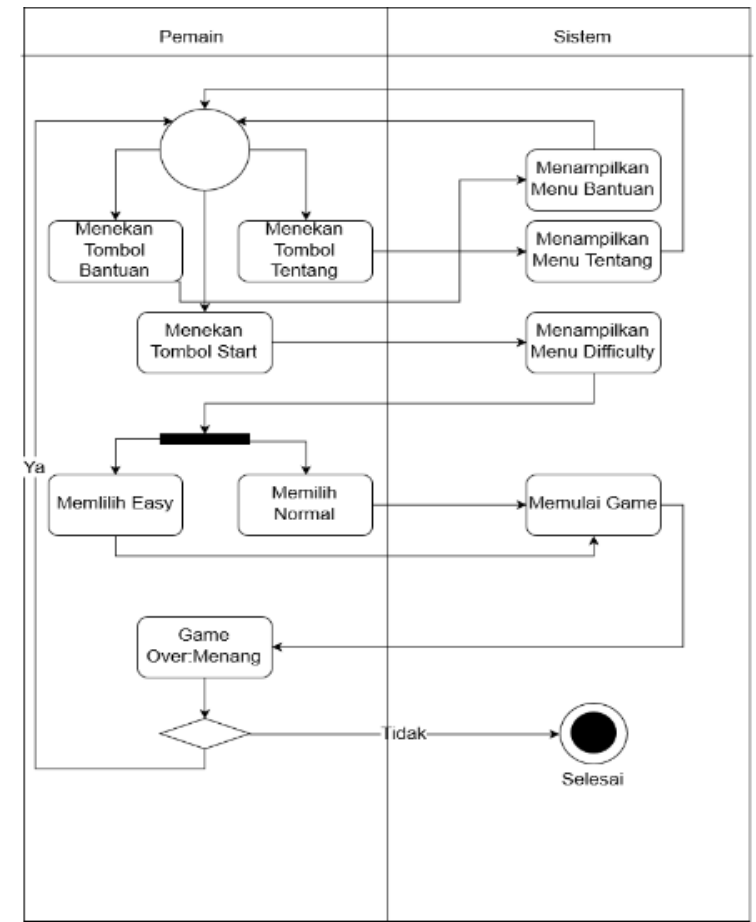

Gambar 3 Activity Diagram Game Hillige Reis

Sequence Diagram digunakan untuk menggambarkan urutan langkah-langkah yang dilakukan sebagai suatu respon dari kejadian untuk menghasilkan output tertentu. Sequence diagram menjelaskan perilaku sistem ketika diberikan input berbeda, yaitu ketika user ingin mengakses tombol bantuan, sistem akan memberikan menu bantuan dan begitu pula dengan menu tentang, dan mulai bermain game (Gambar 4).

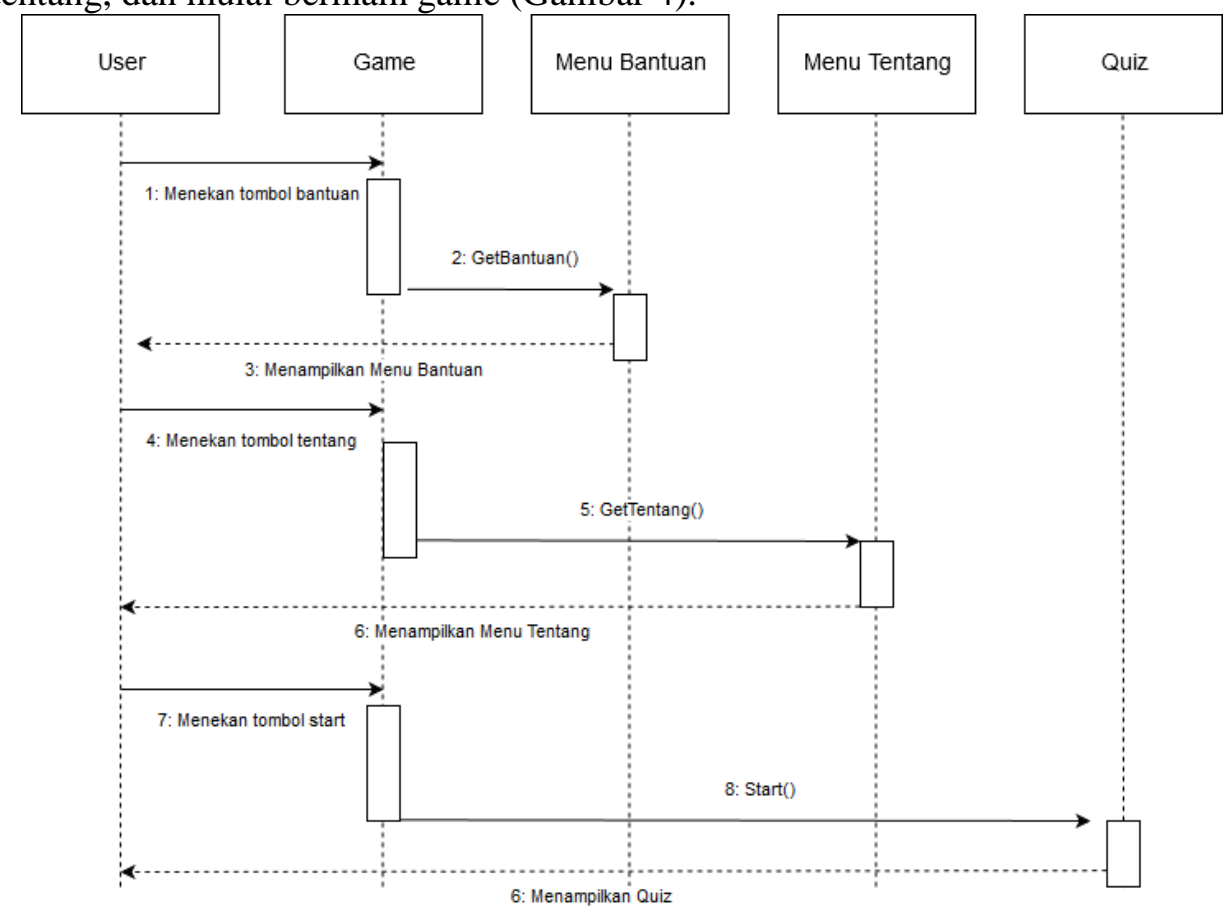

Gambar 4 Sequence Diagram Game Hillige Reis

Diagram kelas atau class diagram menggambarkan struktur sistem dari segi pendefinisian kelas-kelas yang akan dibuat untuk membangun sistem. Diagram kelas dibuat lengkap dengan atribut kelas dan metode-metode yang ada pada kelas tersebut. 


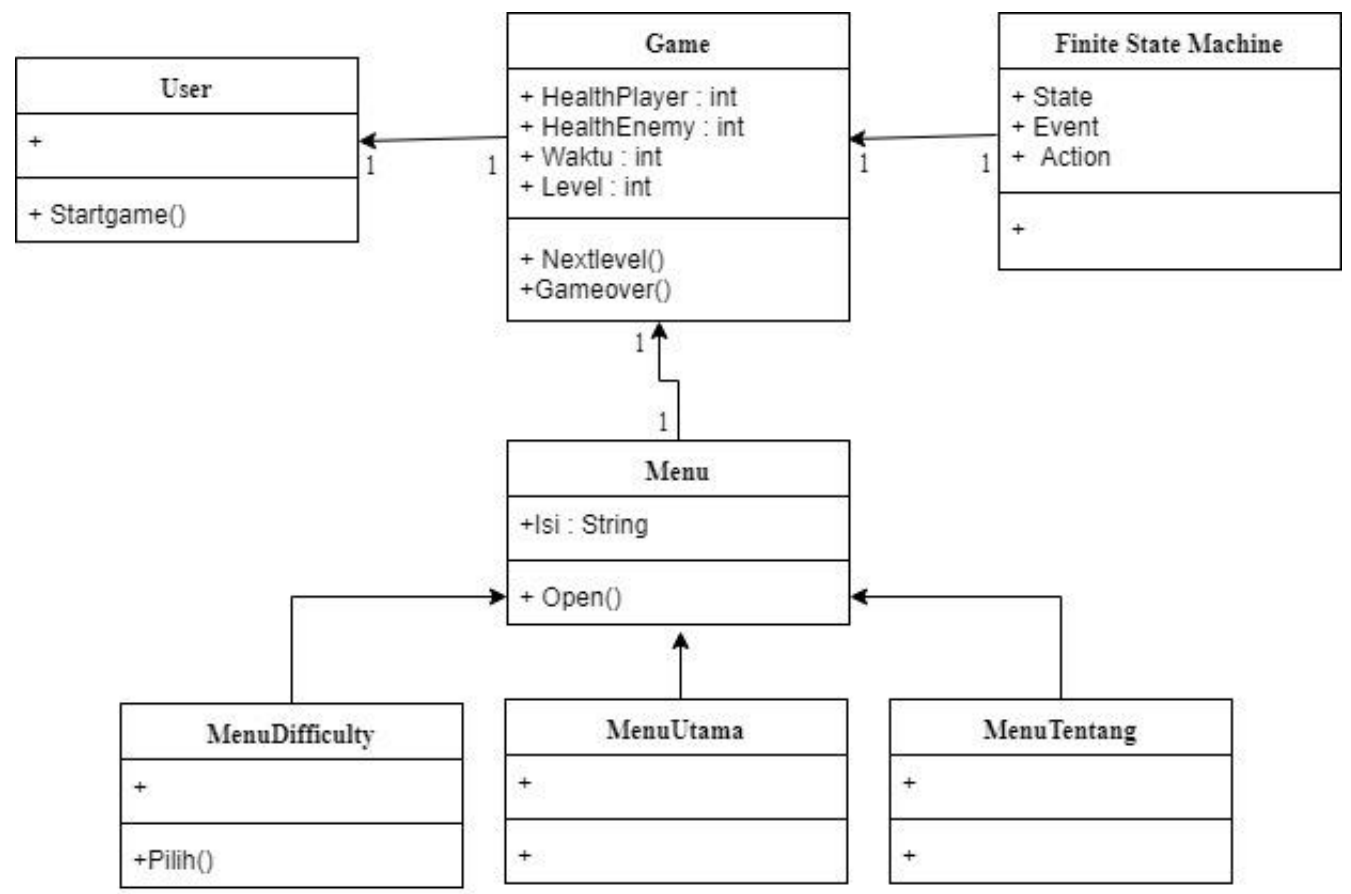

Gambar 5 Class Diagram Game Hillige Reis

\section{Production}

Dari hasil desain objek dan karakter pada tahap pre-produksi, akan direalisasikan pada tahap produksi. Alur permainan akan dirancang dengan penerapan metode finite state machine akan digunakan agar memudahkan perancangan game. Finite State Machine diaplikasikan untuk mengatur alur pada sistem game, agar tidak keliru dan berjalan sebagaimana mestinya jika player sudah memasukkan input maka dengan fsm akan dijelaskan state yang akan diakukan game.

Penerapan finite state machine berupa rule perilaku IF/THEN, yang menjelaskan hubungan antara input/output perilaku Finite State Machine sistem game, yang tersusun seperti berikut:

a. IF Menu Utama AND Masuk Menu Tentang THEN Menu Tentang

b. IF Menu Tentang And Exit Then Menu Utama

c. IF Menu Utama AND Masuk Menu Bantuan THEN Menu Bantuan

d. IF Menu Bantuan AND Exit Then Menu Utama

e. IF Menu Utama AND Tekan Tombol Start THEN Pilih Difficulty

f. IF Pilih Difficulty AND Exit Then Menu Utama

g. IF Pilih Difficulty AND Play Then Keluar Pertanyaan

h. IF Jawab Pertanyan AND jawaban Salah THEN HealthPlayer Berkurang

i. IF Jawab Pertanyan AND jawaban Benar THEN HealthEnemy Berkurang

j. IF Game Over AND HealthPlayer $=0$ THEN kalah

k. IF Game Over AND HealthEnemy $=0$ THEN Menang (Gambar 6) 


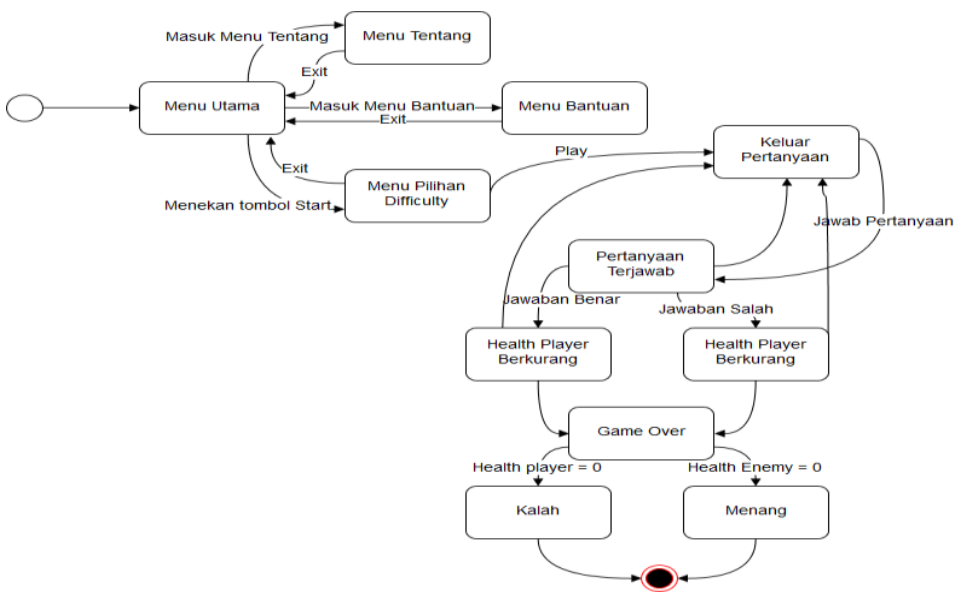

Gambar 6 Finite State Machine Game Hillige Reis

Terdapat tampilan antarmuka dari menu-menu yang terdapat pada game Hillige Reis seperti tampilan menu awal, halaman petunjuk, profil pembuat game, halaman tingkat kesulitan, halaman cerita, dan permainan pada game.

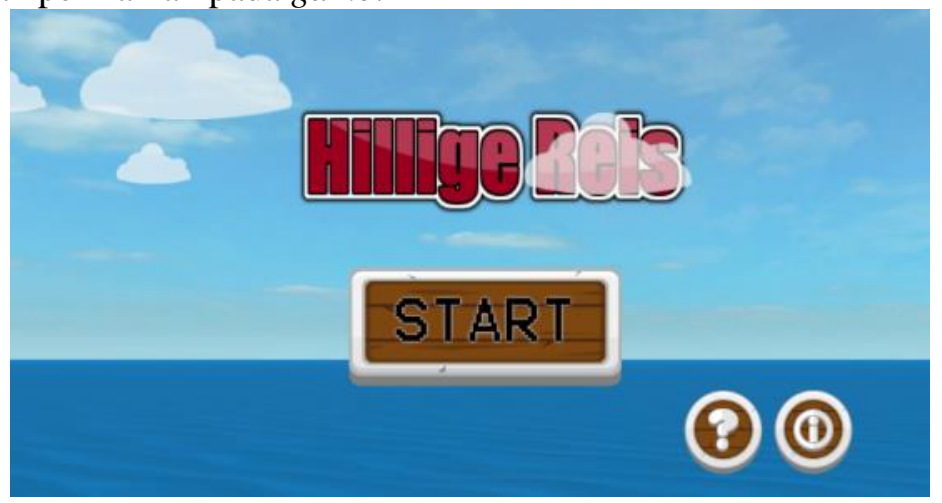

Gambar 7 Tampilan Menu Awal Game Hillige Reis

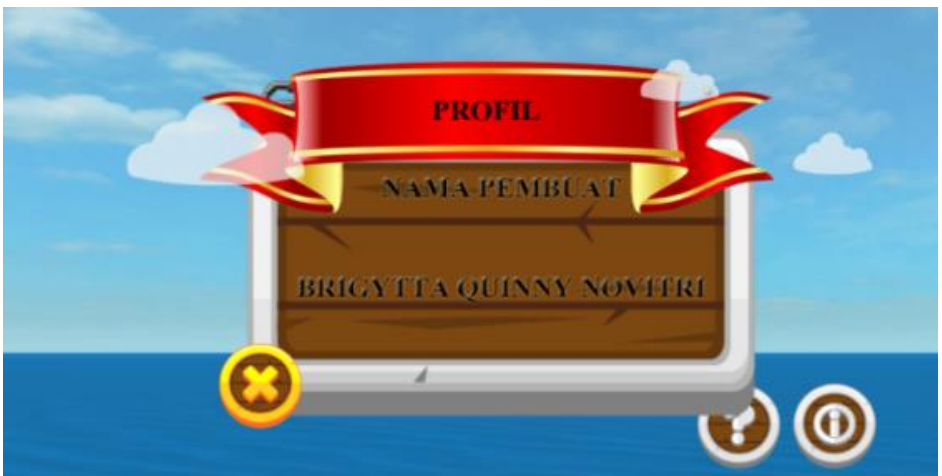

Gambar 8 Tampilan Petunjuk Game Hillige Reis

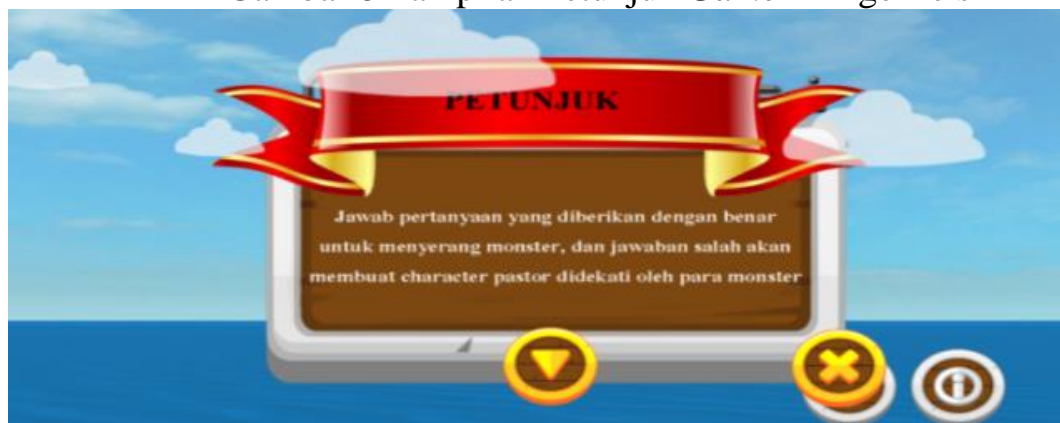

Gambar 9 Tentang Pembuat Game Hillige Reis 


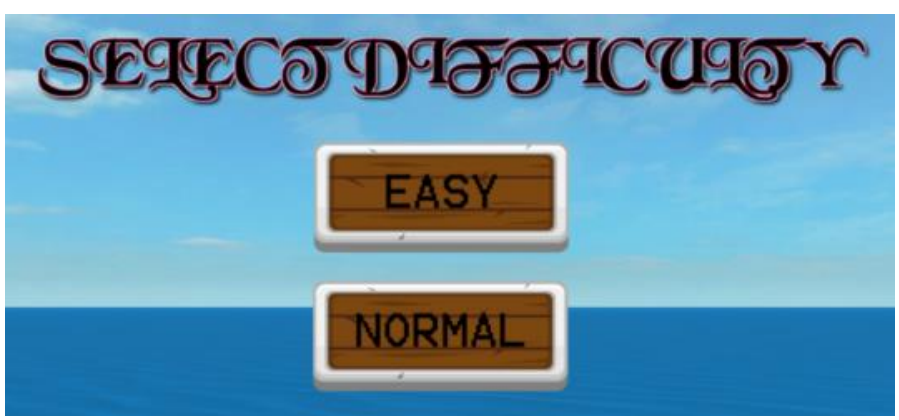

Gambar 10 Tampilan Memilih Tingkat Kesulitan Game Hillige Reis

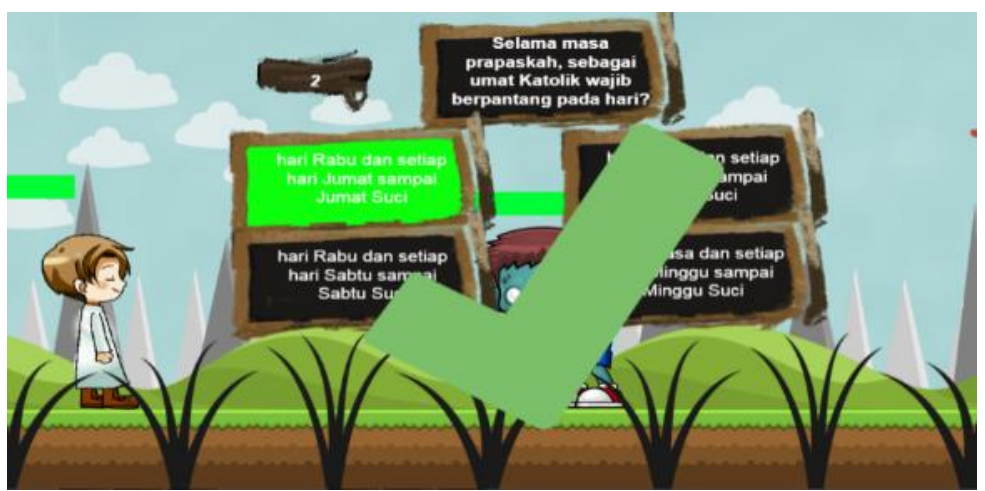

Gambar 11 Tampilan Permainan Game Hillige Reis

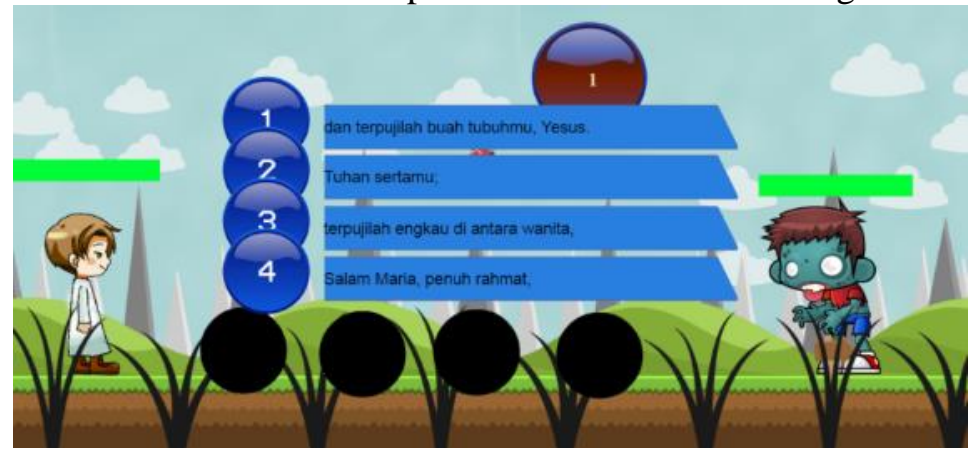

Gambar 12 Tampilan Animasi Game Hillige Reis

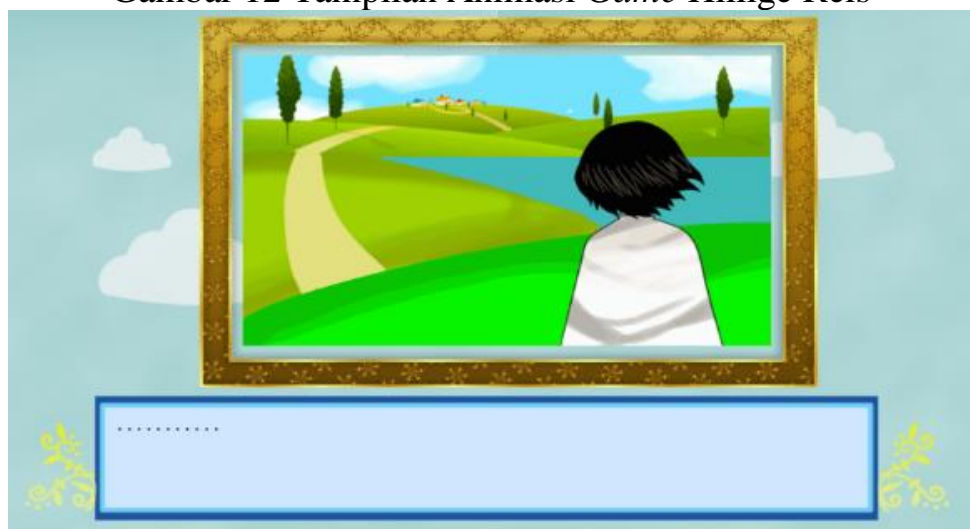

Gambar 13 Tampilan Permainan Menyusun Doa Game Hillige Reis

Testing

Pengujian dan evaluasi perangkat yang disebut juga sebagai AT (Acceptance Test) oleh pengguna juga dilakukan. Pengguna disini adalah 15 responden yang merupakan simpatisan dan beragama katolik yang diberikan kuisioner mengenai hasil dari perangkat lunak yang telah dicoba. Berikut merupakan hasil kuisioner pengujian oleh pengguna : 
Tabel 1 Tabel Hasil Kuesioner dengan Acceptance Testing

\begin{tabular}{|c|l|c|c|c|c|c|}
\hline \multirow{2}{*}{ No. } & \multicolumn{1}{|c|}{ Pertanyaan } & \multicolumn{5}{c|}{ Skala } \\
\cline { 2 - 6 } & SS & S & R & KS & STS \\
\hline 1 & $\begin{array}{l}\text { Apakah tampilan game } \\
\text { menarik? }\end{array}$ & 5 & 9 & 0 & 1 & 0 \\
\hline 2 & $\begin{array}{l}\text { Apakah game edukasi ini } \\
\text { mudah digunakan? }\end{array}$ & 4 & 10 & 1 & 0 & 0 \\
\hline 3 & $\begin{array}{l}\text { Apakah fitur pada game } \\
\text { edukasi ini sudah lengkap? }\end{array}$ & 3 & 9 & 0 & 3 & 0 \\
\hline 4 & $\begin{array}{l}\text { Apakah cerita pada game } \\
\text { edukasi ini menampilkan } \\
\text { informasi yang sesuai dengan } \\
\text { topic? }\end{array}$ & 5 & 8 & 0 & 2 & 0 \\
\hline 5 & $\begin{array}{l}\text { Apakah isi game edukasi } \\
\text { mudah dipahami? }\end{array}$ & 5 & 10 & 0 & 0 & 0 \\
\hline 6 & $\begin{array}{l}\text { Apakah game edukasi ini dapat } \\
\text { menambah wawasan anda/anak } \\
\text { usia dini yang memainkannya? }\end{array}$ & 7 & 7 & 0 & 0 & 0 \\
\hline 7 & $\begin{array}{l}\text { Apakah semua tombol pada } \\
\text { game edukasi dapat berfungsi } \\
\text { dengan baik? }\end{array}$ & 5 & 10 & 0 & 0 & 0 \\
\hline 8 & $\begin{array}{l}\text { Apakah animasi pada game } \\
\text { dapat berjalan baik? }\end{array}$ & 4 & 11 & 0 & 0 & 0 \\
\hline 9 & $\begin{array}{l}\text { Apakah sound/suara pada game } \\
\text { edukasi sudah dapat berfungsi? }\end{array}$ & 3 & 10 & 0 & 2 & 0 \\
\hline 10 & $\begin{array}{l}\text { Apakah tampilan interface pada } \\
\text { game sudah sesuai dengan tema } \\
\text { game? }\end{array}$ & 2 & 13 & 0 & 0 & 0 \\
\hline
\end{tabular}

Tabel 2 Tabel Hasil Olahan Kuesioner dengan Acceptance Testing

\begin{tabular}{|c|c|c|c|c|c|c|c|}
\hline \multirow{2}{*}{ No. } & \multirow{2}{*}{ Pertanyaan } & \multicolumn{5}{|c|}{ Skala } & \multirow{2}{*}{ Jumlah } \\
\hline & & SS*5 & S*4 & $\mathrm{R} * 3$ & $\mathrm{KS} * 2$ & STS*1 & \\
\hline 1 & $\begin{array}{l}\text { Apakah tampilan game } \\
\text { menarik? }\end{array}$ & 25 & 36 & 0 & 2 & 0 & 63 \\
\hline 2 & $\begin{array}{l}\text { Apakah game edukasi ini } \\
\text { mudah digunakan? }\end{array}$ & 20 & 40 & 3 & 0 & 0 & 53 \\
\hline 3 & $\begin{array}{l}\text { Apakah fitur pada game } \\
\text { edukasi ini sudah lengkap? }\end{array}$ & 15 & 36 & 0 & 6 & 0 & 57 \\
\hline 4 & $\begin{array}{l}\text { Apakah cerita pada game } \\
\text { edukasi ini menampilkan } \\
\text { informasi yang sesuai } \\
\text { dengan topic? }\end{array}$ & 25 & 32 & 0 & 4 & 0 & 61 \\
\hline 5 & $\begin{array}{l}\text { Apakah isi game edukasi } \\
\text { mudah dipahami? }\end{array}$ & 25 & 40 & 0 & 0 & 0 & 65 \\
\hline 6 & $\begin{array}{l}\text { Apakah game edukasi ini } \\
\text { dapat menambah wawasan } \\
\text { anda/anak usia dini yang } \\
\text { memainkannya? }\end{array}$ & 35 & 28 & 0 & 0 & 0 & 63 \\
\hline 7 & Apakah semua tombol & 25 & 40 & 0 & 0 & 0 & 65 \\
\hline
\end{tabular}




\begin{tabular}{|c|l|c|c|c|c|c|c|}
\hline \multirow{2}{*}{ No. } & \multicolumn{1}{|c|}{ Pertanyaan } & \multicolumn{5}{|c|}{ Skala } & \multirow{2}{*}{ Jumlah } \\
\cline { 3 - 6 } & SS*5 & S*4 & $\mathrm{R}^{* 3}$ & $\mathrm{KS}^{* 2}$ & $\mathrm{STS} * 1$ & \\
\hline 8 & $\begin{array}{l}\text { pada game edukasi dapat } \\
\text { berfungsi dengan baik? }\end{array}$ & & & & & & \\
\hline 9 & $\begin{array}{l}\text { Apakah animasi pada } \\
\text { game dapat berjalan baik? }\end{array}$ & 20 & 44 & 0 & 0 & 0 & 64 \\
\hline 10 & $\begin{array}{l}\text { Apakah sound/suara pada } \\
\text { game edukasi sudah dapat } \\
\text { berfungsi? }\end{array}$ & 15 & 40 & 0 & 4 & 0 & 59 \\
\hline & $\begin{array}{l}\text { Apakah tampilan interface } \\
\text { pada game sudah sesuai } \\
\text { dengan tema game? }\end{array}$ & 10 & 52 & 0 & 0 & 0 & 62 \\
\hline
\end{tabular}

a. Analisa pertanyaan pertama

Dari tabel diatas dapat dilihat bahwa jumlah nilai 15 responden untuk pertanyaan pertama adalah 63. Nilai rata-ratanya adalah $63 / 15=4.2$. Persentase nilainya adalah $4.2 / 5 * 100 \%=84 \%$. Berdasarkan nilai yang didapatkan dari perhitungan adalah $84 \%$ maka dapat disimpulkan bahwa responden setuju bahwa tampilan game menarik dan $16 \%$ responden tidak setuju bahwa tampilan game menarik.

b. Analisa pertanyaan kedua

Dari tabel diatas dapat dilihat bahwa jumlah nilai 15 responden untuk pertanyaan pertama adalah 53. Nilai rata-ratanya adalah 53/15=3.5. Persentase nilainya adalah $3.5 / 5 * 100 \%=70 \%$. Berdasarkan nilai yang didapatkan dari perhitungan adalah $70 \%$ maka dapat disimpulkan bahwa responden setuju bahwa game edukasi mudah digunakan dan $30 \%$ responden tidak setuju bahwa game edukasi mudah digunakan.

c. Analisa pertanyaan ketiga

Dari tabel diatas dapat dilihat bahwa jumlah nilai 15 responden untuk pertanyaan pertama adalah 57. Nilai rata-ratanya adalah 57/15 $=3.8$. Persentase nilainya adalah $3.8 / 5 * 100 \%=76 \%$. Berdasarkan nilai yang didapatkan dari perhitungan adalah $76 \%$ maka dapat disimpulkan bahwa responden setuju bahwa fitur pada game edukasi sudah lengkap dan $24 \%$ responden tidak setuju bahwa fitur pada game edukasi sudah lengkap.

d. Analisa pertanyaan Keempat

Dari tabel diatas dapat dilihat bahwa jumlah nilai 15 responden untuk pertanyaan pertama adalah 61. Nilai rata-ratanya adalah $61 / 15=4$. Persentase nilainya adalah $4 / 5 * 100 \%=80 \%$. Berdasarkan nilai yang didapatkan dari perhitungan adalah $80 \%$ maka dapat disimpulkan bahwa responden setuju bahwa game edukasi menampilkan informasi yang sesuai topik dan $20 \%$ responden tidak setuju bahwa game edukasi menampilkan informasi yang sesuai topik.

e. Analisa pertanyaan kelima

Dari tabel diatas dapat dilihat bahwa jumlah nilai 15 responden untuk pertanyaan pertama adalah 65. Nilai rata-ratanya adalah $63 / 15=4.3$. Persentase nilainya adalah $4.3 / 5 * 100 \%=86 \%$. Berdasarkan nilai yang didapatkan dari perhitungan adalah $86 \%$ maka dapat disimpulkan bahwa responden setuju bahwa isi game edukasi mudah dipahami dan $14 \%$ responden tidak setuju bahwa isi game mudah dipahami.

f. Analisa pertanyaan keenam

Dari tabel diatas dapat dilihat bahwa jumlah nilai 15 responden untuk pertanyaan pertama adalah 63. Nilai rata-ratanya adalah $63 / 15=4.2$. Persentase nilainya adalah $4.2 / 5 * 100 \%=84 \%$. Berdasarkan nilai yang didapatkan dari perhitungan adalah $84 \%$ maka dapat disimpulkan bahwa responden setuju bahwa game edukasi ini dapat menambah wawasan anak usia dini yang memainkannya dan $16 \%$ responden tidak setuju bahwa game edukasi ini dapat menambah wawasan anak usia dini yang memainkannya. 
g. Analisa pertanyaan ketujuh

Dari tabel diatas dapat dilihat bahwa jumlah nilai 15 responden untuk pertanyaan pertama adalah 65. Nilai rata-ratanya adalah $65 / 15=4.3$. Persentase nilainya adalah $4.3 / 5 * 100 \%=$ $86 \%$. Berdasarkan nilai yang didapatkan dari perhitungan adalah $86 \%$ maka dapat disimpulkan bahwa responden setuju bahwa semua tombol pada game edukasi dapat berfungsi dengan baik dan $14 \%$ responden tidak setuju bahwa tombol pada game edukasi dapat berfungsi dengan baik.

h. Analisa pertanyaan kedelapan

Dari tabel diatas dapat dilihat bahwa jumlah nilai 15 responden untuk pertanyaan pertama adalah 64. Nilai rata-ratanya adalah $64 / 15=4.26$. Persentase nilainya adalah $4.26 / 5 * 100 \%=$ $85 \%$. Berdasarkan nilai yang didapatkan dari perhitungan adalah $85 \%$ maka dapat disimpulkan bahwa responden setuju bahwa animasi pada game dapat berjalan dengan baik dan $15 \%$ responden tidak setuju bahwa animasi pada game dapat berjalan dengan baik.

i. Analisa pertanyaan kesembilan

Dari tabel diatas dapat dilihat bahwa jumlah nilai 15 responden untuk pertanyaan pertama adalah 59. Nilai rata-ratanya adalah 59/15=3.9. Persentase nilainya adalah $3.9 / 5 * 100 \%=$ $78 \%$. Berdasarkan nilai yang didapatkan dari perhitungan adalah $78 \%$ maka dapat disimpulkan bahwa responden setuju bahwa suara pada game edukasi dapat berfungsi dan $22 \%$ responden tidak setuju bahwa suara pada game edukasi dapat berfungsi.

j. Analisa pertanyaan kesepuluh

Dari tabel diatas dapat dilihat bahwa jumlah nilai 15 responden untuk pertanyaan pertama adalah 62. Nilai rata-ratanya adalah $62 / 15=4$. . Persentase nilainya adalah $4.1 / 5 * 100 \%=$ $82 \%$. Berdasarkan nilai yang didapatkan dari perhitungan adalah $82 \%$ maka dapat disimpulkan bahwa responden setuju bahwa tampilan interface pada game sudah sesuai dengan tema game dan $18 \%$ responden tidak setuju bahwa tampilan interface pada game sudah sesuai dengan tema game.

\section{Post-Production}

Pada tahap post-production game sudah dianggap layak dimainkan dan dapat dijalankan pada komputer maupun laptop. Jika memainkan gamenya melalui komputer, maka perangkat keras yang diperlukan untuk menjalankan game edukasi yaitu motherboard, Central Processing Unit minimal menggunakan intel core i3, Random Access Memory (RAM), minimal menggunakan memori 2gb, Video Graphic Array (VGA), Harddisk Driver (HDD), monitor, keyboard, mouse, dan optical disc (drive).

\section{KESIMPULAN}

Berdasarkan hasil perancangan yang telah dilakukan pada game Hillige Reis ini, maka pada penelitian ini memaparkan beberapa kesimpulan yang didapat dari hasil analisis dan perancangan dari penelitian ini yaitu teknik pengumpulan data yang digunakan adalah dengan melakukan Studi Literatur, Dokumentasi, Observasi, dan Angket/Kuesioner pada Game edukasi yang telah ada sehingga mendapatkan data yang penting untuk menjadi dasar dalam pembuatan Game edukasi Hillige Reis. Perancangan Game Hillige Reis menggunakan metode Game Development Life Cycle (GDLC) yang dimulai dari tahap pre-production, tahap production, tahap testing, dan sampai pada proses post-production. Game Hillige Reis ini dibuat dengan menggunakan permodelan sistem menggunakan Unified Modelling Language (UML) yang dirancang dengan menggunakan game engine Construct 2. Ada pun proses pengujian game yang telah dibangun menggunakan pengujian Blackbox dan acceptance test. Perancangan game edukasi ini bertujuan untuk memperdalam pengetahuan tentang agama katolik untuk usia Sekolah Dasar (SD) dengan konsep edutainment (education and entertainment). Perancangan game edukasi ini bertujuan untuk menjawab permasalahan cara penggunaan metode finite state machine untuk mengatur jalannya alur sistem. 


\section{SARAN}

Saran yang dapat diberikan untuk untuk meningkatkan efektivitas dan performa serta untuk membuat game ini semakin menarik, yaitu tampilan dari game edukasi ini masih sangat sederhana, dari tampilan menu awal, sampai dengan menu game, untuk penelitian kedepannya dapat mendesain agar tampilan dari game edukasi lebih menarik. Dalam perancangan game edukasi dan game modern masa kini, telah digunakan grafis 3d, agar lebih menarik. Untuk itu perlunya grafis yang bagus agar semakin menarik pemain untuk memainkannya. Pilihan penggunaan game engine Construct 2 untuk membuat game edukasi yang simple, menarik dan efektif dalam performe merupakan hal yang baik, akan tetapi dalam sisi fleksibilitas Construct 2 belum cukup baik, karena tidak dapat menunjang grafis $3 \mathrm{~d}$, Script untuk mempercepat perfoma game juga sangat susah diimplementasi karena tidak termasuk dalam fitur Construct 2, untuk penelitian selanjutnya dapat menggunakan Game engine yang fleksibel seperti Unreal Engine dan Unity. Untuk kedepannya agar game edukasi mempunyai fitur untuk bermain secara online dengan sesama user maupun bermain dengan NPC.

\section{DAFTAR PUSTAKA}

[1] Ayu, S.F., Sutardi., Tajidun, LM., 2017, Rancang Bangun Game Edukasi Puzzle Kebudayaan Sulawesi Tenggara Dengan Algoritma Fisher-Yates Shuffle, Jurnal semanTIK, Vol. 3 No. 1 - ISSN: 2502-8928, , diakses tgl 13 September 2018.

[2] A.Ainul, 2012, Implementation of Simulation Game Method on Subjects to Improve Study Result and Learning Motivation of Students, Thesis, Universitas Negeri Sembilan.

[3] Yandi, 2014, Pembangunan Game Edukasi Sistem Pencernaan Manusia Berbasis Dekstop, Fakultas Ilmu Komputer Universitas Komputer Indonesia, Bandung.

[4] Setyawan, Fx. Sulis Bayu., Sutarman, Maman, 2014, Buku Guru Pendidikan Agama Katolik dan Budi Pekerti, Jakarta: Kementerian Pendidikan dan Kebudayaan.

[5] M.T., Mulyani, 2010, Pelaksanaan Pendidikan Agama di SMA Katolik Soverdi Kabupaten Badung Bali, Jurnal Analisa Volume XVII No. 02 Juli, diakses tgl 13 September 2018

[6] Listia, dkk 2007, Problematika Pendidikan Agama di Sekolah (Hasil Penelitian tentang pendidikan Agama di Kota Jogyakarta 2004-2006), Jogyakarta, Interfidei

[7] Rahadian, Miftah F., Suyatno, Addy., Maharani, Septya., 2016, Penerapan Metode Finite State Machine Pada Game "The Relationship", Jurnal Informatika Mulawarman, Vol. 11 No. 1, diakses tgl 13 September 2018.

[8] Ekojono, Irawati,D.A., Affandi, Lugman, Rahmanto, A.N., 2017, Penerapan Algoritma Fisher-Yates Pada Pengacakan Soal Game Aritmatika, Jurnal Prosiding SENTIA 2017, Volume 9,ISSN:20852347, diakses tgl 13 September 2018.

[9] H.M. Chandler, 2010, Game Production Handbook (Book Style), Sudbury : Jones and Bartletts Publishers. 